\title{
Morphological description of the digestive canal in Taeniopygia guttata (zebra finch) and Sturnus vulgaris (starling)
}

\author{
Ameer M. Taha ${ }^{1 *}$ iD and Abdulaziz S. AL-Duleemy ${ }^{2}$
}

\begin{abstract}
Background: The present study is designed to identify the morphological description of the digestive tract in two species of different birds; these birds were Taeniopygia guttata (zebra finch) which is granivorous and Sturnus vulgaris (Starling) which is omnivorous.

Results: The results showed that the digestive canal of both birds was similar in the essential structure. It begins with the oropharyngeal cavity, which starts with the beak. The beak appeared different in the outer shape, which depends on the feeding. The mouth palate in both birds contains slit localized in the hard palate. This slit represents as beak nostril. The tongue appeared at the bottom of the oropharyngeal cavity. The esophagus appeared as a muscular tube containing the crop, which is divided into two parts the cervical part and the thoracic region, while the stomach was composed of two clear parts in both birds. The first one was a conical shape called proventriculus. The second was a spherical shape called the gizzard, and they are separated by a transitional zone called the isthmus, which was more apparent in the zebra finch, while the small intestine developed mostly in both birds. It is divided into three parts, which were the duodenum, jejunum, and ileum, as well as the large intestine, which appeared as tube shape, which is the rectum. There was a pair of caecum located in the contact area of the ileum and rectum. The digestive canal ends with the cloaca in both birds.
\end{abstract}

Conclusion: These results indicate that there are differences in the anatomical structure of the gastrointestinal tract organs between the two birds to be compatible with the quality and method of obtaining food.

Keywords: Comparative anatomy, Digestive canal, Starling, Zebra finch

\section{Introduction}

Birds are among the animals that possess a group of distinctive characteristics that distinguish them from the rest of the animals, such as having wings that help them fly in the sky. However, not all of them can fly with their possession of wings such as penguins, ostriches, and kiwis (Gill et al. 2017). Birds have essential roles in the environment, as some types of birds carry out pollination in plants by transferring pollen grains while feeding on these plants, such as hummingbirds. Birds are

\footnotetext{
* Correspondence: amhamdany@uomosul.edu.iq

'Biology Department/Education college for pure sciences, Mosul University, Mosul, Iraq

Full list of author information is available at the end of the article
}

also an important link in the food chain, many of them feed on plants, and some of them feed on animals such as falcons that feed on other animals, some of which feed on fish like a gannet, which is itself an essential food for other animals such as pets and reptiles. It has also been an important food for humans for hundreds of years (Jerome and Jerome 2010).

Birds need food to sustain growth and reproduction. The food passes through mechanical and chemical processes and with multiple and successive steps that start with obtaining food and ending with waste excretion outside the body. The feeding process can be summarized in simple steps that are finding food, grinding, and swallowing it and then entering the digestive path in its

\section{Springer Open}

(๑) The Author(s). 2020 Open Access This article is licensed under a Creative Commons Attribution 4.0 International License, which permits use, sharing, adaptation, distribution and reproduction in any medium or format, as long as you give appropriate credit to the original author(s) and the source, provide a link to the Creative Commons licence, and indicate if changes were made. The images or other third party material in this article are included in the article's Creative Commons licence, unless indicated otherwise in a credit line to the material. If material is not included in the article's Creative Commons licence and your intended use is not permitted by statutory regulation or exceeds the permitted use, you will need to obtain permission directly from the copyright holder. To view a copy of this licence, visit http://creativecommons.org/licenses/by/4.0/. 
various compositions; after completing digestion, waste is thrown out of the body (Mayntz 2017). The digestive system of birds shows a considerable variation in their shape and composition depending on the food quality, the evolution of different strains, and environmental conditions (Davis 2007).

The digestive system in birds generally consists of the oropharyngeal cavity, the gastrointestinal tract, and its glandular appendices. The digestive system begins with the mouth that is surrounded by a keratinized structure known as the beak that differs in their shape according to the method of feeding and the nature of food; it has an essential role in feeding birds, as it contributes significantly to obtaining food. The mouth contains the tongue, which has a different shape and size, according to the species of birds, how they fed, and the nature of their food (Ritchison 2006). The mouth is connected to the esophagus, which is divided into three parts, which are the cervical esophagus, the crop, and the thoracic esophagus (Shehan 2012; Zhu 2015), then the stomach, which consists of two parts, the glandular stomach or proventriculus and the gizzard. The proventriculus is responsible for chemical digestion as it appears wellformed in carnivorous birds, whereas the gizzard is responsible for mechanical digestion, and it has a good composition in granivorous birds (Catroxo et al. 1997; Hamdi et al. 2013; Gelis 2013). Then, in the small intestine and the large intestine, and there may be a pair of caecum at the area of contact in the small intestine with the large intestine, or there may not be. The caecum differs in their shape, size, and histological composition in different types of birds according to the nature of the food (Coles et al. 2007). The rectum is finally opened by the cloaca. At the same time, the glands include simple and complex glands that are found in the oropharyngeal cavity, tongue, esophageal wall, and proventriculus, as well as glands attached to the digestive system, the liver, and the pancreas (Aksoy and Cinar 2009).

Therefore, the study aimed to identify the composition and morphological characteristics of the digestive canal in two types of birds. These are the starling Sturnus vulgaris, who live in the Iraqi environment naturally, and the zebra finch Taeniopygia guttata that is one of the ornamental birds imported to Iraq.

\section{Material and methods}

The dissection process was performed after the birds were anesthetized with chloroform (5 birds from each type), following the guidelines given by the Ethics Committee of the Canadian Council on Animal Care (CCAC) (certification \# 2010-015), and then transferred to the large anatomy dish and placed on its backs and its ends tied with pins, and the abdomen opened from the middle after carefully removing the feathers from the ventral thoracic region and cutting the cavity bone. After recording the macroscopic anatomical notes on the different parts of the digestive canal, the entire digestive canal of the bird was removed from the tongue to the cloaca very carefully treated with precision anatomy tools. It was transferred to glass dishes containing a physiological solution (normal saline (0.75\%)) (Al-Hajj, 2010) to visualize the digestive canal and take measurements of the rest of the anatomical results.

\section{Results}

The results of the current study show that the digestive canal in both birds is an uneven straight twisted channel that started with the mouth and ended in the cloaca. The average length of the digestive canal in the zebra finch is $17 \pm 0.12 \mathrm{~cm}$, whereas the average length of the digestive canal in the starling is $31 \pm 0.23 \mathrm{~cm}$. The digestive canal in the two birds composed of several parts that differ in length and thickness between the two birds on one side and in the digestive canal of one bird on the other (Figs.1 and 2).

The mouth represents the beginning of the gastrointestinal canal in research birds. It is composed of the oropharyngeal cavity, surrounded on the outside by the horny beak (B) covering the jawbones as it consists of an upper beak (UB) covering the upper jaw and a lower beak (LB) covering the lower jaw of both birds (Figs. 3 and 4). The zebra finch beak appeared orange, triangular,

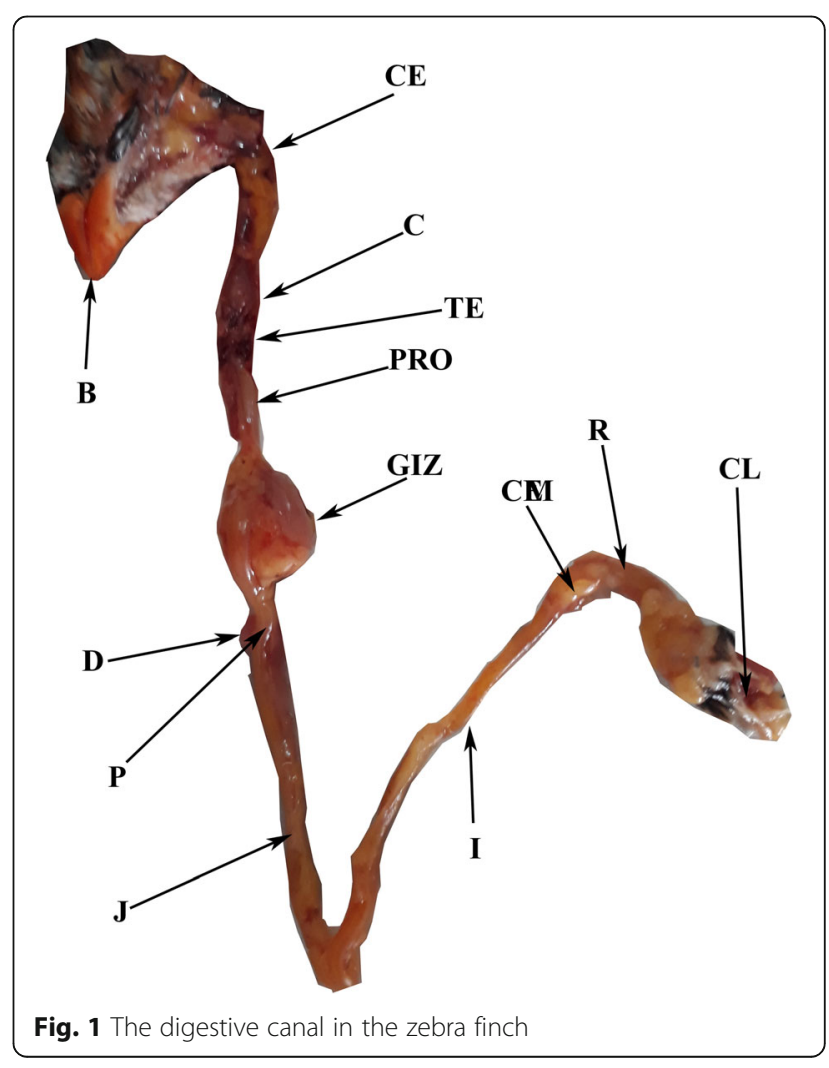




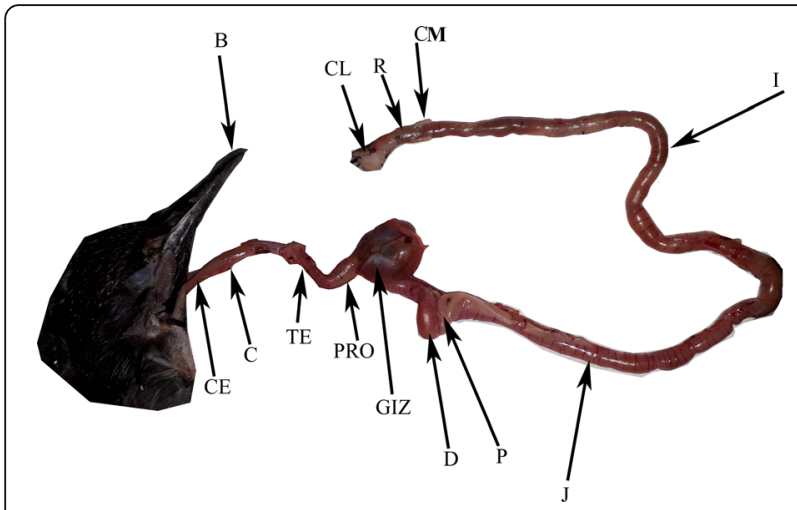

Fig. 2 The digestive canal in the starling

and curved from its central part. The lower edge of the upper beak corresponds to the top edge of the lower beak completely, giving the beak a pyramidal shape when closed (Fig. 3). The upper beak appeared slightly taller than the lower beak. The average length of the upper beak was $1 \pm$ $0.02 \mathrm{~cm}$ and width $3-4 \mathrm{~mm} \pm 0.04$, while the length of the lower beak was $(8 \mathrm{~mm})$ and its width $3-4 \mathrm{~mm} \pm 0.12$. Starlings' beak appeared elongated and with a notably tapered end. Its color is black in most of its parts and white in other parts, the upper jaw was longer than the lower jaw, and the middle part of the upper jaw appeared prominent and broader than the rest of its parts. They are at the base of two openings of the nostril $(\mathrm{N})$ that are large and elongated in shape; the average length of the upper beak is $3.5 \pm 0.32$ $\mathrm{cm}$ while the average width is $4 \pm 0.012 \mathrm{~mm}$. The lower beak appeared shorter and thicker than the upper beak; its average length is $3 \pm 0.22 \mathrm{~cm}$, while the average width is 3.5 $\pm 0.36 \mathrm{~mm}$. And its lower part from its base to the middle of it is in the form of a groove towards the inside with a triangular shape, as they are at the bottom of the lower beak, oval grooves are identical to the nairs in the upper beak. Still, they are not open (Fig. 4).

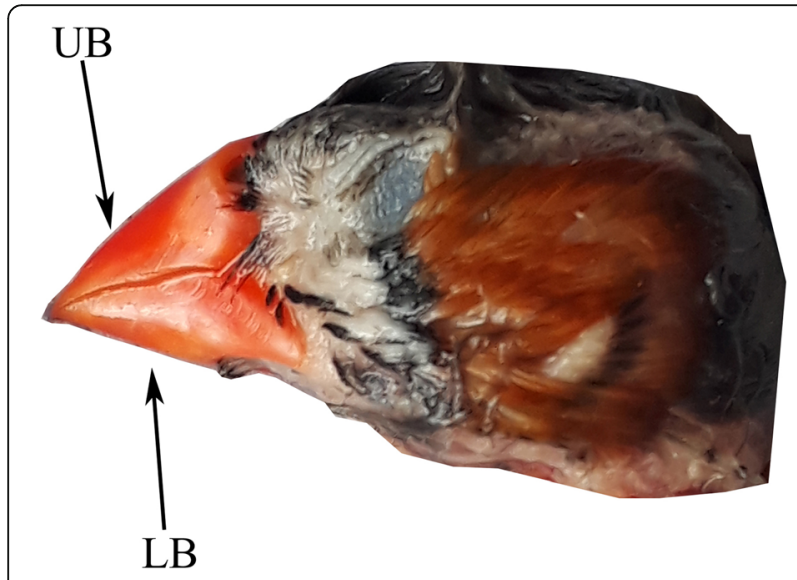

Fig. 3 The beak in the zebra finch

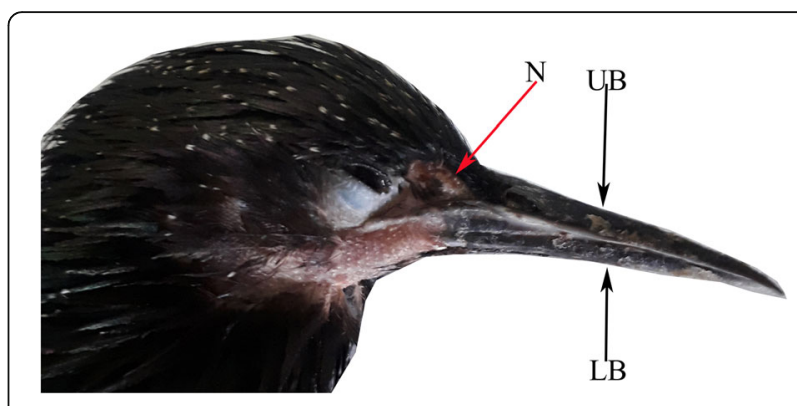

Fig. 4 The beak in the starling

The roof of the mouth (MR) appeared in both birds containing a longitudinal slit located within the hard palate that represents the choanal slit (NF). Its average length in the zebra finch is $5-6 \pm 0.32 \mathrm{~mm}$ and the average width is $2 \pm$ $0.03 \mathrm{~mm}$, while the length in the starling is $1.5 \pm 0.43 \mathrm{~cm}$ and the average width is $4 \pm 0.04 \mathrm{~mm}$ (Figs. 4 and 5). Zebra finch contain many longitudinal papillae (PAP) distributed randomly in all parts of the roof of the mouth. Still, it becomes more uniform around the sides of the rostral nostril. These papillae interfere with each other at the beginning of the choanal slit, but they diverge from each other as we head toward the base of the nostril (Fig. 5), while in starlings, longitudinal papillae appeared longer compared with zebra finch and also appeared randomly distributed in all parts of the roof of the mouth, but the longest papillae appeared on the sides of the rostral cavity. The top of the oropharyngeal cavity has two at the base and one at the top. There are about ten longitudinal papillae intertwined with each other towards the base of the nostril as in the zebra finch (Fig. 6).

The tongue $(\mathrm{T})$ resides in both birds at the bottom of the oropharyngeal cavity and between the edges of the lower beak. It appeared in the zebra finch elongated with a triangular end like a spear, and its top does not reach the end of the lower jaw. It reached an average length of $7 \pm 0.042 \mathrm{~mm}$ and an average width of $1 \pm 0.002 \mathrm{~mm}$. Its color appeared white with a light black end. At its broad

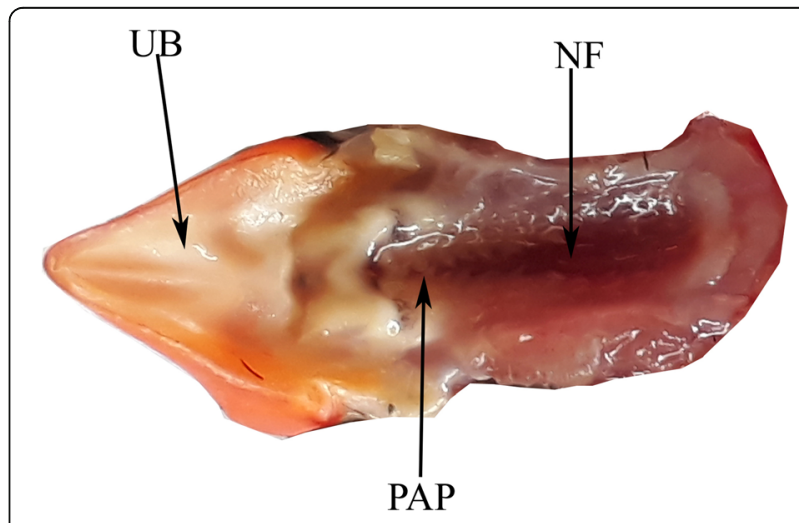

Fig. 5 The mouth roof in the zebra finch 


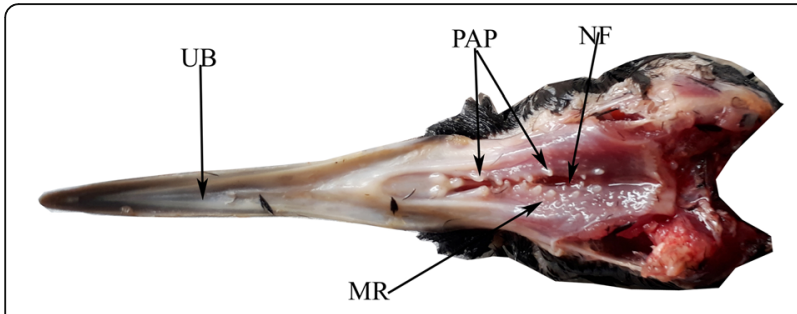

Fig. 6 The mouth roof in the starling

base, there are two rows separated by filamentous papillae, which are known as lingual papillae, a row on each side, and the color of the tongue in front of these papillae on the side is black (Fig. 7). Starling's tongue appeared in a lengthy leafy shape with a slotted end (LE) that is in the form of bristles numbering 3 capillaries at the end of the tongue, and the top of the tongue does not reach the end of the lower jaw as in zebra finch, but it is more pronounced than in it. The side edges of the tongue are elevated up from the center of the tongue, giving the tongue the shape of the calf. The tongue also appeared in a highly transparent white form, so that its internal structures were visible. As in zebra finch, two rows of lingual papillae appeared on either side of the tongue. The tongue seemed longer than it is in the zebra finch with an average length of $1.5 \pm 0.22 \mathrm{~cm}$ and a width of $2 \pm 0.02 \mathrm{~mm}$ (Fig. 8). In both birds, the tongue

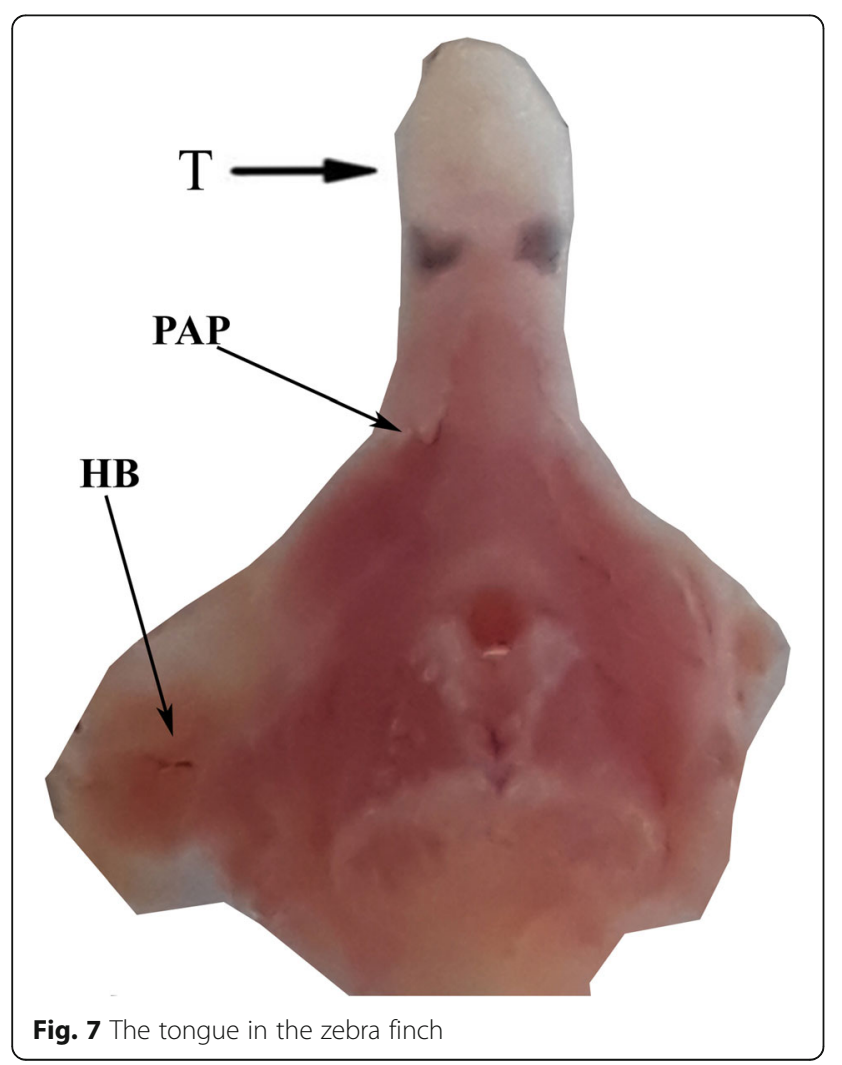

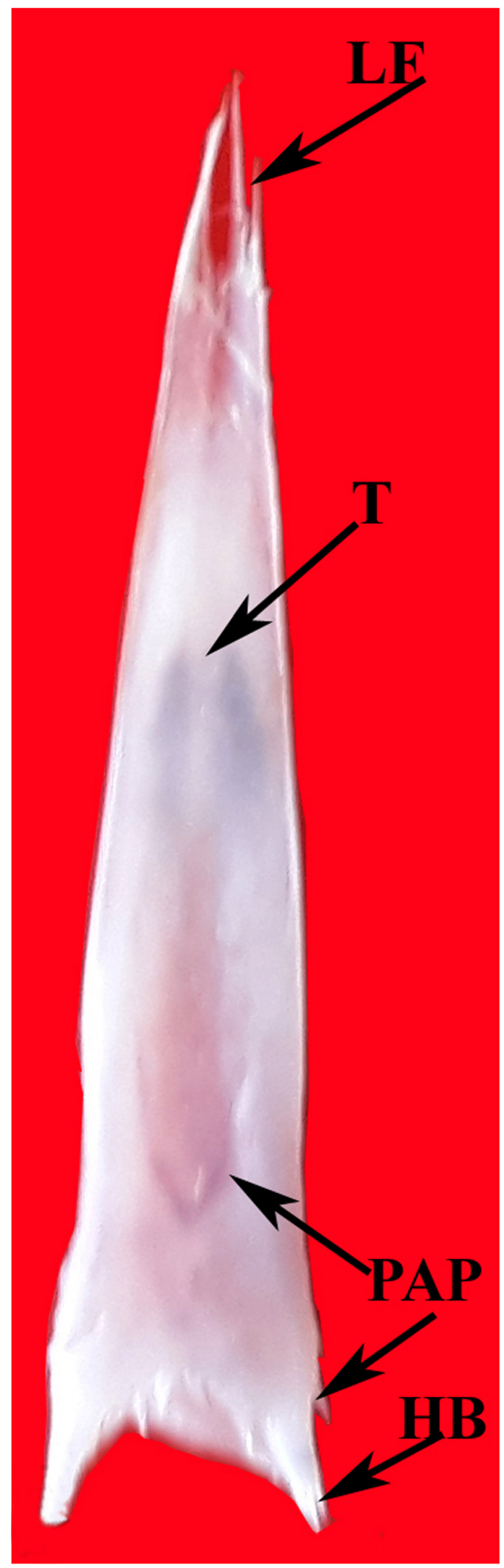

Fig. 8 The tongue in the starling 
is attached to the two hyoid bones (HB), which take the shape of the number ( $\lambda$ in Arabic) around the esophagus (Figs. 7 and 8).

The esophagus appeared in the research birds in the form of a muscular tube that connects the oral pharyngeal cavity from the upper side and the proventriculus (PRO) from the lower side (Figs. 1 and 2). In the zebra finch, the esophagus appeared in a large tube with relatively transparent walls that continue to exist along the esophagus. The average length of the esophagus from the oropharyngeal cavity to the proventriculus is 3 $\pm 0.22 \mathrm{~cm}$, while the average diameter is $1 \pm 0.01 \mathrm{~cm}$. The esophagus expands in the middle of it to be a crop (C) that shows two-lobed pear-shaped pinnacles and its top facing up. Its base towards the bottom is clearly distinguished into two rooms and pink color, but it is darker than the rest of the esophagus and has thick walls which are more pronounced than in the starlings. It also contains internal longitudinal folds. The average length of the crop was $5 \pm 0.02 \mathrm{~mm}$ and the average width was $3 \pm 0.001 \mathrm{~mm}$ (Fig. 1). The esophagus is divided into two parts; the upper part, or what is known as the cervical esophagus (CE), connects the oral pharyngeal cavity and the crop, with an average length of $2 \pm 0.1 \mathrm{~cm}$. In contrast, the lower part, or what is known as the thoracic esophagus (TE), connects the crop and proventriculus with an average length of $1 \pm 0.12 \mathrm{~cm}$. The thoracic esophagus is darker in color and more equipped with blood compared to the cervical esophagus (Fig. 1).

Starling's esophagus appeared in a more pronounced muscle tube than in the zebra finch, and its walls are of a high blood supply compared to its counterpart in the zebra finch. Its walls appear pink in color, and its inner walls contain continuous longitudinal folds along the esophagus as in the zebra finch. The average length of the esophagus is $6 \pm 0.31 \mathrm{~cm}$ while the average diameter is $2 \pm 0.03 \mathrm{~mm}$, as in the zebra finch. The crop appeared almost spindle and whose walls are similar to the walls of the esophagus, and therefore, it is difficult to distinguish them from the rest of the esophagus. The inner lining of the crop contains longitudinal folds that increase its area, and its average length of the gland is $6 \pm 0.06 \mathrm{~mm}$ and its average diameter is $4 \pm 0.022 \mathrm{~mm}$ (Fig. 2). As in the zebra finch, the crop in the starlings divided the esophagus into an upper or cervical esophagus, with an average length of $4 \pm 0.12 \mathrm{~cm}$, and a lower or thoracic esophagus with an average length of $2 \pm 0.09 \mathrm{~cm}$. The cervical esophagus, as in the zebra finch, is lighter in color and has less vascular equipment compared to the thoracic esophagus (Fig. 2).

The stomach appeared in the two birds divided into two parts, a front part known as the glandular stomach or proventriculus and a posterior part known as the muscular stomach or gizzard (GIZ), separated by a small transition region known as the isthmus (IS). The proventriculus of zebra finch appeared in the sperm, conical shaped, its top towards the esophagus, and its base towards the gizzard, with walls similar to the thoracic esophagus but with a higher blood supply (Figs.1 and 9). The average length of the proventriculus is $5 \pm$ $0.012 \mathrm{~mm}$ and its diameter is $1.5 \pm 0.002 \mathrm{~mm}$, and lined from the inside are many grooves and shallow folds, while the proventriculus in the starlings appeared in a conical shape, like the zebra finch, but their walls are thicker, brighter, and have a very high blood supply compared to the zebra finch (Figs. 2 and 10). The inner lining contains folds and grooves and is more pronounced than in the zebra finch; the average length of the proventriculus is $1.5 \pm 0.3 \mathrm{~cm}$, and the average diameter is $5 \pm 0.1 \mathrm{~mm}$. The isthmus region appeared in the form of a transparent part between the two stomachs in the zebra finch (Figs. 1 and 9). In contrast, in the starlings, this area did not appear clearly, as it was difficult to distinguish this region between the two stomachs (Figs. 2 and 10).

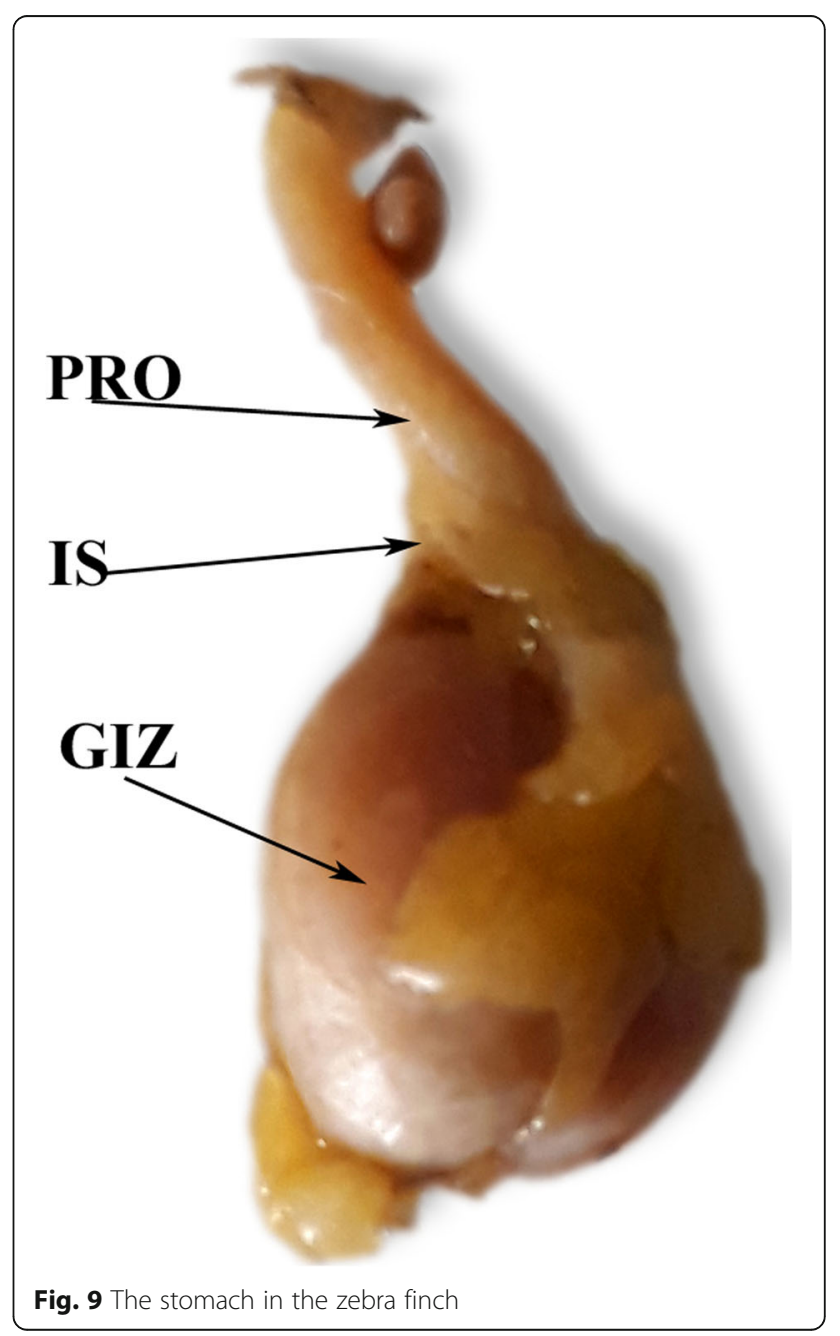




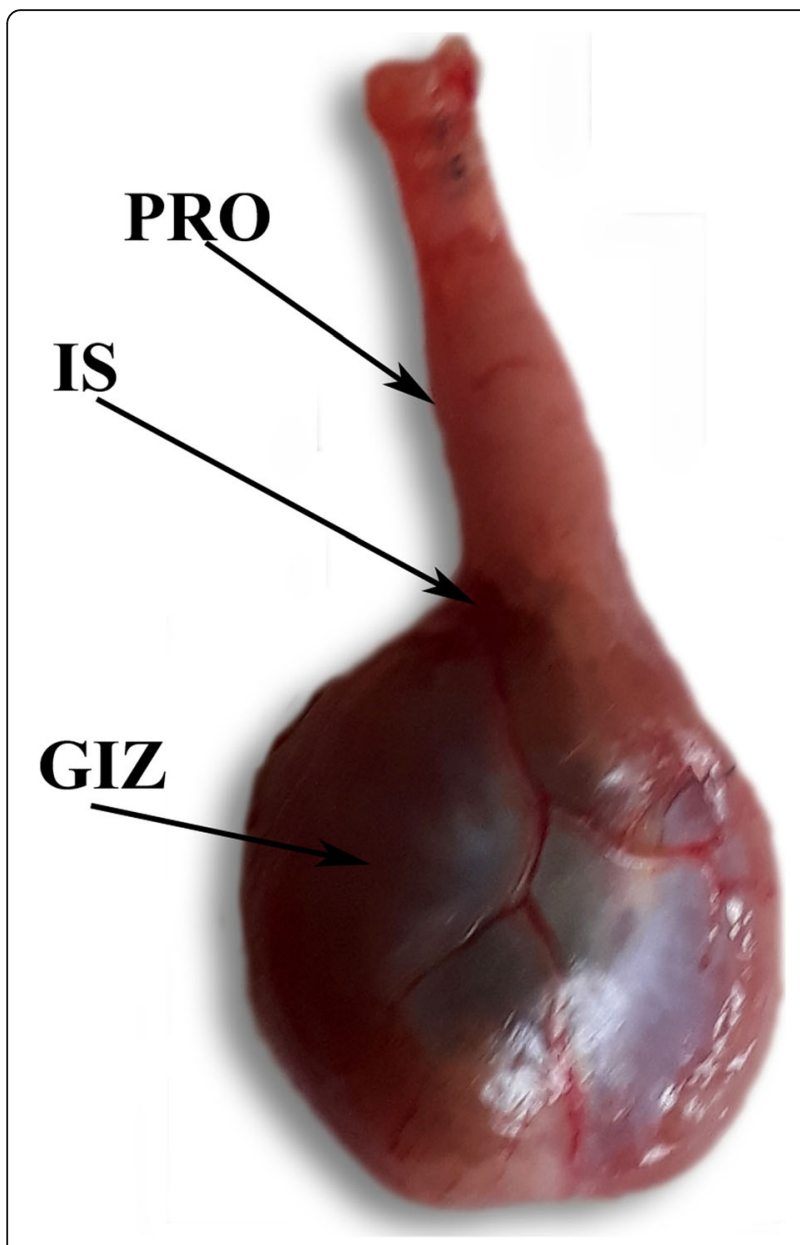

Fig. 10 The stomach in the starling

While the gizzard appeared as a solid muscular structure in both birds, in the zebra finch, the gizzard has a disc or circular shape and is pink in color, and the contact area of the duodenum with the gizzard is close to the glandular gastric region of the gizzard from the ventral side of the gizzard, and their walls have a high blood supply and a diameter of $1 \pm 0.05 \mathrm{~cm}$ (Figs. 1 and 9). The gizzard lined on the inside with a thick, yellowishgreen layer known as koillin or cuticle; this layer contains many longitudinal folds and is parallel to each other. Also found inside the gizzard are many small pebbles. Starlings' gizzard was a disc, or spherical shape appeared pink as it is in the zebra finch. Still, it has the advantage that it has a very high vascular preparation higher than that in the zebra finch as well as in other parts of the digestive tract of the starling with an average diameter of $1.3 \pm 0.42 \mathrm{~cm}$. Also, the gizzard differs from in the zebra finch in the areas of glandular and duodenum contact in the gizzard; the proventriculus contacted in the middle of the upper end of the gizzard while the duodenum contacted the middle of the lower end of the gizzard (Figs. 2 and 10). As in the zebra finch gizzard, it is a line in the starlings with a layer of koillin or cuticle, which also appeared in a yellowish-green color with long parallel folds, but it was more profound than that in the zebra finch and also contained small pebbles.

The small intestine appeared highly developed for both birds and divided into three regions, the duodenum (D), jejunum (J), and ileum (I). The length and diameter of each part vary between the two birds on one side and the digestive tract of one bird on the other (Figs. 1 and 2 ). In the zebra finch, the average length of the small intestine is $10.5 \pm 0.6 \mathrm{~cm}$. The first areas of the small intestine which connect to the gizzard are the duodenum that appeared in the shape of a letter $U$ confined between its arms the pancreas (P). It is light pink, and a high blood supply has reached an average length of $2.5 \pm$ $0.32 \mathrm{~cm}$ and an average diameter of $2 \pm 0.01 \mathrm{~mm}$. For jejunum and ileum, they are in the form of laps numbering (2.5 laps). The jejunum and ileum appeared in yellowish-pink color and had less blood supply than in the duodenum (Fig. 1). The average length of the jejunum is $1 \pm 0.1 \mathrm{~cm}$ and the average diameter is $2 \pm 0.2$ $\mathrm{mm}$, while the average length of the ileum is $7 \pm 0.7 \mathrm{~cm}$ and the average diameter is $1.8 \pm 0.02 \mathrm{~mm}$. The inner lining of the small intestine contains many villi that spread along the small intestine.

In the starlings, the small intestine appeared longer and thicker than the zebra finch, as it reached an average length of $20 \pm 0.6 \mathrm{~cm}$ and is also composed of parts (Fig. 2). As in the zebra finch, the duodenum appeared as a letter $\mathrm{U}$ in white color, and reddish and bloody equipment is high and contains between its arms the pancreas; it has an average length of $5 \pm 0.15 \mathrm{~cm}$ and an average diameter of $3-4 \pm 0.02 \mathrm{~mm}$. As for the jejunum and ileum, it will be 3 laps or rings with color and bloody preparation almost identical to that in the duodenum. The average length of the jejunum is $4 \pm 0.42 \mathrm{~cm}$ and the average diameter is $3-4 \pm 0.01 \mathrm{~mm}$, while the average length of the ileum is $11 \pm 0.8 \mathrm{~cm}$ and the average diameter is $3 \pm 0.02 \mathrm{~mm}$. The inner lining of the starling also contains a large number of villi protruding from the mucous layer (Fig. 2).

The small intestine in the two birds is followed by the large intestine that appeared in both research birds in the form of a non-branched or twisted tubular structure known as the rectum $(\mathrm{R})$, which appeared in the zebra finch with a pink to yellow color with a wider diameter than the ileum. But its bloody preparation is almost identical to that of the ileum. Its average length is $7 \pm$ $0.12 \mathrm{~mm}$ and the diameter is $2 \pm 0.2 \mathrm{~mm}$. The area of contact with the rectum is a pair of a very small cecum (CM). They are difficult to see with the naked eye, and these ceca were attached to the outer layer of the rectum (Fig. 1). The rectum in the starling has appeared longer and thicker than it is in the zebra finch, and it was dark 
pink and with high blood supply; the average length is 1 $\pm 0.3 \mathrm{~cm}$, and the average diameter $3 \pm 0.02 \mathrm{~mm}$. Also, it was found that a pair of cecum appears in the contact area with the rectum and that is distinguished from them in the zebra finch as they are larger and easily identifiable and have a white color with a tubular shape and attached to the outer wall of the rectum. The average length of the cecum reached $2-3 \pm 0.01 \mathrm{~mm}$ in diameter $(0.5 \pm 0.002 \mathrm{~mm})$ (Fig. 2). The inner lining of the rectum appeared containing longitudinal folds of a villus-like shape for both search birds.

The digestive tract of the two birds ends with the cloaca $(\mathrm{CL})$, which is the exit site for the products of the digestive, reproductive, and urinary systems. It appears in both birds in the form of an expanded structure of a diameter more significant than the diameter of the rectum and opens to the outside by a transverse incision (Figs. 1 and 2).

\section{Discussion}

The results of the current study showed that the digestive canal in the starlings is longer than the digestive canal in the zebra finch. Since the starlings are from omnivorous birds, they need length in the digestive canal to achieve proper digestion, whereas the zebra finch feeds on grains, its digestive tract appears short because it feeds on one type of food. That is consistent with a study by Al-Hamdany (2012), as the parrot's digestive canal seems relatively short because it depends on a specific type of food as it exfoliates the grains before eating them, which facilitates digestion. The same applies to the digestive canal in the love bird Melopsittacus undulatus (Hamad 2008). It also observed that the digestive canal is longer in other types of omnivorous birds, such as chicken, ducks, turkeys, geese, and Jackdaw bird (Ibrahim 2000; Hamad 2008). These results are confirmed in a study (Starck and Rahmaan 2003). This study showed that the length of the digestive canal is proportional to the food of the bird and its ability to digest and absorb it.

The results indicated that the mouth in both birds is composed of the oral pharyngeal cavity, which is surrounded from the outside by the beak. The beak is pyramidal in the zebra finch and a protracted shape in the starlings; as in the sandgrouse, the oropharyngeal cavity appeared long and surrounded by its beak, which seemed to be conical (Al-Jeraisy, 2017), and the shape of the beak in the research birds is appropriate to the way it fed. The shape of the beak is related to the food habits of the bird, and this is confirmed by studies in the heron and duck beak as the beak has serrated edges like a saw and helps them to catch fish. In contrast, the carnivorous birds have sharp, short beaks that torn out the flesh of its prey; the parrot has a separate beak that acts as a nutcracker; and the woodpecker has a sharp beak that is used to dig tree trunks (Ritchison 2006).

The roof of the mouth appeared in both birds containing a longitudinal fissure located within the hard palate, representing this choanal slit. The roof of the mouth of the zebra finch appeared with many longitudinal papillary distributed randomly in all parts of the roof of the mouth. It also appeared in many birds, such as Meleagris gallopavo and the love bird (Hamad 2008; Sayed et al. 2016), while the longitudinal papillae in starling appeared more developed and grown compared to the zebra finch. This is what has been observed in most birds such as guinea fowl, parrot, and gull, as the roof of the mouth appeared in the three birds containing the rostral nostril incision, and on both sides of this fissure, there are papillae in the three birds called nostril papillae. These papillae help in the process of swallowing and directing the condyle towards the esophagus, as well as preventing it from reversing and the occurrence of the vomiting process, and perhaps, the papillae in the research birds do the same function (Al-Hamdany 2012).

The tongue settles at the bottom of the oropharyngeal cavity and between the edges of the lower beak for both birds, and this is what appeared in most birds (AbouZaid 2008; Al-Nefeiy and Alahmary, 2015; Başak et al. 2017). It appeared in the zebra finch elongated with a triangular end similar to the spear which does not reach the top of the lower jaw, and the spear shape of the tongue appeared in the guinea fowl and sandgrouse (AlHamdany 2012; Al-Jeraisy 2017). The starling's tongue appeared in a lengthy leafy shape with a slotted end, and its top does not reach the end of the lower jaw; the tongue slotted also appeared in the seagull, as it looked like the tongue of the snake (Al-Hamdany 2012). This result was recorded in the tongue of the owl as well (Emura and Chen 2008). Lingual papillae appeared in the tongue of the two birds in two rows of lingual papillae, and this is similar to what appeared in most birds, such as gulls, sandgrouse, oracles, and parasites. These papillae give a coarse appearance to the tongue, which helps to stabilize, adhere to, and moisturize food before swallowing, and this is similar to its function in previous studies of birds (Al-Hamdany 2012; Al-Jeraisy 2017).

The esophagus appeared longer in the starlings than in the zebra finch, and the length of the esophagus is related to the size of the food intake because the long esophagus can expand more than the short esophagus (Hassani 2000). Starlings may need the long esophagus to moisten the food intake for as long as possible, while the zebra finch does not need it because it feeds on one type of food. It was observed in the esophagus of both birds the presence of the crop, which divides the esophagus into two parts and is darker in color and more equipped with blood. The cervical part is longer than 
the thoracic region, and this resembles its counterpart in many birds, such as the turkey, doves, sandgrouse, and guinea fowl (Chechnya 2006; Al-Hamdany 2012; AlJeraisy, 2017; Zaher et al. 2012), likewise in Lanius tephronotus (Zhu 2015). In the zebra finch, the twolobed crop appeared, and this is consistent with what appeared in the parrot (Al-Hamdany 2012). Also, this agrees with Hassani (2000) that all carnivorous birds have a double-lobe crop. The crop in the starling was a spindle that was difficult to distinguish, and this corresponds to the black-winged falcon, Elanus caeruleus, as the giblets are spindle that is difficult to identify when it is empty and appears visible when it is full. The research birds need the crop to obtain the storage and moisture of food because most of their food is relatively robust (Hamdi et al. 2013).

The stomach appeared in both birds consisting of two parts, the proventriculus and the gizzard, and this is confirmed by most studies that deal with birds (Zaher et al. 2012; Hamdi et al. 2013; AL-Juboory et al. 2016; Al-taee 2017). The proventriculus in both birds appeared conical with a secretory chemical activity, and this is consistent with the proventriculus of doves, sandgrouse, parrot, Coturnix coturnix, and most birds (Hamad 2008; Al-Hamdany 2012; Zaher et al. 2012). The results showed the presence of the median isthmus region that separated the proventriculus from the gizzard and was evident in the zebra finch. That was also seen in forest pigeon birds (AL-Juboory et al. 2016) as well as in the study of Ogunkoya and Cook (2009) and the sandgrouse (Al-Jeraisy, 2017). It did not appear clearly in the starling, as it was difficult to notice, and this is consistent with the white owl, as this region was not observed (ALJuboory et al. 2016). That also indicates that the stomach in the zebra finch is of a simple type while in the starling is of a complex type.

The gizzard was a disc or circular for both birds and with an abundant blood supply and also appeared in studies (Al-Hamdany 2012; Al-Jeraisy 2017; Zaher et al. 2012). Gizzard appeared in the sandgrouse and parrot in a pirated form, and gizzard appeared in the Coturnix coturnix of a spherical shape. Gizzard contained small pebbles as in most birds, such as sandgrouse, parrot, and guinea fowl, which also appeared in the current study of birds (Al-Hamdany 2012; Al-Jeraisy 2017). The research results showed that gizzard is lined with koillin and has a role in mechanical digestion as in pigeon birds and white owl (AL-Juboory et al. 2016).

The results showed that the small intestine was variable in length between the two birds, as it appeared long in the starlings compared to its counterpart in the zebra finch. The length of the intestine is related to the intake of food since the starling is considered to be multifeeding omnivorous birds, so it needs a long intestine to increase absorption. While in the zebra finch, it feeds on the grains after their peeling, which facilitates their digestion. That is confirmed by a study (Hrabar and Perrin 2002). The reason for this is that it is peeling the pills before eating them other than the latter. At the same time, it is noted that the intestine of the Jackdaw bird is relatively long due to the diversity of its food (Hamad 2008). That also agrees with the results of the study conducted on the sandgrouse, which is one of the omnivorous birds that requires long small intestine for complete nutritional digestion of food (Al-Jeraisy, 2017). The results of the current research also showed that the small intestine highly developed in both birds, and it is divided into three regions which are the duodenum, jejunum, and the ileum. That is similar to many birds, such as the duck and the brown falcon Falco berigora, as the intestine appeared divided into the same regions and the ileum is the longest part (Rana et al. 2016; AL-taee 2017; Khaleel and Atiea 2017). It was inconsistent with the study on the small intestine of the E. caeruleus falcon, which is characterized by two primary parts, the duodenum and the ileum (Hamdi et al. 2013). The duodenum appeared for both birds in the shape of a U-like buttonhole. The pancreas is located between its arms, and this is what appeared in most birds, such as the brown hawk F. berigora, guinea fowl, and ducks (Al-Hamdany 2012; Al-Jeraisy 2017; Al-taee 2017; Khaleel and Atiea 2017). The jejunum and ileum are in the form of rolls, the number of which varies according to type (3 rolls) in the starlings and ( 2.5 rolls) in the zebra finch, and this case also appeared in other birds as the small intestine is in the form of rolls as in studies (Al-Hamdany 2012; AlJeraisy 2017). The reason for this is to reduce the overall size of the intestine to fit into the abdominal cavity which is relatively small.

The large intestine appeared in both birds in an unbranched or twisted tubular structure known as the rectum. The same case was in most birds such as the brown falcon $F$. berigora (Al-taee 2017), as well as in the sandgrouse and the Tauri pigeon, as the large intestine formed from the rectum (Chechnya 2006; Al-Jeraisy 2017). There also found a pair of cecum that appear in the contact area between the ilium and rectum; this is what appeared in many birds, such as the brown falcon, the common quail, and the owl (Abd EL-Wahab et al., 2017; AL-taee 2017).

The digestive tract ends in the zebra finch and starling of the cloaca, which is the exit site for the products of the digestive, reproductive, and urinary system, and that is similar to its counterpart in most studied birds such as the sandgrouse; it is also found in the Tauri pigeon, Jackdaw, love bird $M$. undulates, guinea fowl, seagull, and parrot (Chechnya 2006; Hamad 2008; Al-Hamdany 2012; Hamdi et al. 2013). 


\section{Conclusion}

The study concluded that there are differences in the anatomical structure of the digestive tract organs between the two birds to be compatible with the quality and method of obtaining food, and this helps them to adapt to the environment in which they live and the ease of getting and digesting food.

\section{Abbreviations}

B: Beak; CM: Cecum; CE: Cervical esophagus; CL: Cloaca; C: Crop;

D: Duodenum; GIZ: Gizzard; HB: Hyoid bones; I: Ileum; IS: Isthmus; J: Jejunum; PAP: Longitudinal papillae; LB: Lower beak; NF: Choanal slit; N: Openings of nostril; P: Pancreas; PRO: Proventriculus; R: Rectum; MR: Roof of the mouth; LE: Slotted end; T: Tongue; UB: Upper beak

\section{Acknowledgements}

The authors would like to express their thanks to the comparative anatomy of vertebrate laboratory in the Biology Department, College of Education for Pure Sciences, Mosul University, for their help during the study.

\section{Authors' contributions}

SAS, AGG, FM, BAE, SED, and DIG designed and performed this work. The authors read and approved the final manuscript.

\section{Funding}

No funding sources

\section{Availability of data and materials}

No dataset was analyzed in the current study.

\section{Ethics approval and consent to participate}

Not applicable

\section{Consent for publication}

All authors agree to the publication.

\section{Competing interests}

The authors declare that they have no competing interests.

\section{Author details}

${ }^{1}$ Biology Department/Education college for pure sciences, Mosul University, Mosul, Iraq. ${ }^{2}$ Nineveh Governorate Education Directorate, Mosul, Iraq.

Received: 17 March 2020 Accepted: 4 May 2020

Published online: 19 May 2020

\section{References}

Abd EL-Wahab, S. M., Farrag, A. H., EL Deeb, R. M., \& EL Atawy, S. A. (2017). Comparative histological and ultrastructural studies on the rectal caeca of three birds. Middle East Journal of Applied Sciences., $7(2), 250-261$

Abou-Zaid, D. F. A. (2008). Comparative anatomical study on the dorsal surface structure of the tongue of two birds with different habits. The Egyptian Journal of Experimental Biology (Zoology), 4, 65-72.

Aksoy, A., \& Cinar, K. (2009). Distribution and ontogeny of gastrin-and serotoninimmunoreactive cells in the proventriculus of developing chick, Gallus gallus domestica. J. Vet. Sci., 10(1), 9-13.

Al-Hajj, H. A. (2010). Optical Microscopy, Theory and Practice, Al-Masirah House for Publishing, Distribution, and Printing, First Edition, Amman - Jordan, p. 238. In Arabic

Al-Hamdany, A. M. (2012) . Comparative anatomical, histological with developmental study at light and electron microscopic level of eye and alimentary canal for three species of birds which differ in nutrient nature. Ph.D. Thesis. Education college, Mosul University. In Arabic.

Al-Jeraisy, F. N. (2017). Anatomical histological study and histochemical comparison of the digestive system in three types of vertebrates belonging to three different classes. In Master Thesis, College of Education for Pure Sciences. Iraq: University of Mosul In Arabic.

Al-Juboory, R. W., Dauod, H. A. M., \& Al-arajy, A. S. (2016). Comparative anatomical and histological study of the stomach in two Iraqi birds (Columba palumbus and Tyto alba). Ibn Al-Haitham J. for Pure \& Appl. Sci, 29(2), 1-12.

Al-Nefeiy, F. A., \& Alahmary, B. A. (2015). Morphological, histological and histochemical studies of the lingual salivary glands of the rock dove, Patagioenas livia (Columbidae). International Journal of Current Research and Academic Review., 3(8), 280-289.

Al-taee, A. A. (2017). Macroscopic and Microscopic Study of Digestive Tract of Brown Falcon Falco berigora in Iraq. Babylon J. for Pure and Appl Sci., 25(3), 915-935.

Başak, F., Atalgin, Ş. H., \& Bozkurt, E. Ü. (2017). Tongue and lingual salivary glands of the canary: scanning electron microscopy and histochemical study. Folia Morphol., 76(3), 348-354.

Catroxo, M. H., Lima, M. A. \& Cappellaro, C. E. (1997). Histological aspects of the stomach (proventriculus and gizzard) of the red-capped cardinal (Paroaria gularis gularis). Rev. Chil. Anat.15:19-27.

Chechnya, A.I. (2006). Anatomical and histological study of the digestive tract in two types of cereal-eating birds, (Columba livia Gmelin, 1789) and carnivores, and sparrow birds (Accipiter nisus Linnaeus, 1758), Master Thesis, College of Science, Tikrit University, Iraq.

Coles, B. H., Krautwald-Junghanns M., Orosz, S. E. \& Tully, T. N. (2007). Essentials of avian medicine and surgery. Blackwell Science Ltd, a Blackwell Publishing Company. P.22;148.

Davis, S. (2007). Endozoochory in the subtropical thicket: comparing effects of species with different digestive system on seed fate.M.sc. Thesis,Faculty of science, Nelson mandela metropolitan university.

Emura, S., \& Chen, H. (2008). Scanning electron microscopic study of the tongue in the owl (Strix uralensis). Anat. Hist. Embry., 37, 475-478.

Gelis, S. (2013). Evaluation and treating the gastrointestinal system. Clini. Av. Medic. 1(14).412-416.

Gill, F., Austin, L., \& Robert W.(2017) Storer, "Bird/Animal ",Encyclopedia .Britannica. https://www.britannica.com/animal/bird-animal/Flight

Hamad, R. S. (2008). Histological and histological comparison study of the gut of the lovebird (Melopsittacus undulates Gould, 1840) and the Zagh (Corvus $f$. Frugilegus Linnaeus, 1758), Master Thesis, College of Science, Tikrit University, Iraq. In Arabic.

Hamdi, H., El-Gareeb, A., Zaher, M., \& AbuAmod, F. (2013). Anatomical, histological and histochemical adaptations of avian alimentary canal to their food habits. II-Elanus caeruleus. Int. J. Sci. \&En. Res, 4(10), 13551364.

Hassani, D. H. (2000). Physiology of poultry, Dar Al-Kutub Printing and Publishing. Baghdad: Directorate In Arabic.

Hrabar, H. D. K., \& Perrin, M. (2002). The effect of bill structure on seed selection by granivorous birds. Afri. Zool., 37(1), 67-80.

Ibrahim, I. K. (2000). Poultry nutrition, Dar Al-Kutub for Printing and Publishing, University of Mosul. Iraq. Pp., 27-42 In Arabic.

Jerome, B. A. \& Jerome, S. Z. (2010). The life of birds. Visual Learning Company. www.visuallearningco.com.

Khaleel, I. M. \& Atiea, G. D. (2017). Morphological and histochemical study of small intestine in indigenous ducks (Anas platyrhynchos). Agric. and Veter. Sci. J. V. 10 (7): 19-27

Mayntz, M. (2017). How do bird eat /Digestion Facts. "http://www.thospruce. com $\backslash$ digestion-Facts For Birds -38437"

Ogunkoya, Y. O., \& Cook, R. D. (2009). Histomorphology of the proventriculus of three species of Australian Passerines: lateralis and Poephila guttata. Anat. Histol. Embry., 38, 246-253.

Rana, J., Dhote, B., Ambwani, T. K., \& Patel, S. K. (2016). Histochemical studies on small intestine of uttara fowl. Inter.Jo. of Sci. Envi and Tech., 5(3), $1181-1188$.

Ritchison, G. (2006). Digestive system: food and feeding habits. Department of Biological Sciences: Eastern Kentucky University www.yardbirds.org.il/ computer/digestion.pdf.

Sayed, A. K., Saleh, A. M., Ahmed, K. A., \& Abdall, K. E. H. (2016). Gross anatomical, light and scanning electron microscopic studies on the pharyngeal roof of turkey (Meleagris gallopavo): comparative study. J. of Adv. Veter. Res., 6(4), $112-117$.

Shehan, N. A. (2012). Anatomical and histological study of esophagus in geese (Anser anser demesticus). Bas.J.Vet. Res., 11(1), 13-22. 
Starck, J. M., \& Rahmaan, A. G. H. (2003). Phenotypic flexibility of structure and function of the digestive system of Japanese quail. J. Exp. Biol., 206, 18871897.

Zaher, M., El-Ghareeb, A., Hamdi, H., \& AbuAmod, F. (2012). Anatomical, histological and histochemical adaptations of the avian alimentary canal to their food habits:-1-Coturnix coturnix. Life Sci. J., 9(3), 253-275.

Zhu, L. (2015). Histological study of the oesophagus and stomach in grey-backed shrike (Lanius tephronotus). Int. J. Morphol., 33(2), 459-464.

\section{Publisher's Note}

Springer Nature remains neutral with regard to jurisdictional claims in published maps and institutional affiliations.

Submit your manuscript to a SpringerOpen ${ }^{\circ}$ journal and benefit from:

- Convenient online submission

- Rigorous peer review

- Open access: articles freely available online

High visibility within the field

- Retaining the copyright to your article

Submit your next manuscript at $\boldsymbol{\nabla}$ springeropen.com 